\title{
C-H bond amination by iron-imido/nitrene species
}

\author{
ZHANG Long \& DENG Liang* \\ State Key Laboratory of Organometallic Chemistry, Shanghai Institute of Organic Chemistry, Chinese Academy of Sciences, Shanghai 200032, \\ China
}

Received December 26, 2011; accepted February 7, 2012; published online April 28, 2012

\begin{abstract}
$\mathrm{C}-\mathrm{H}$ amination by iron-imido/nitrene species has attracted increasing research interest in recent years because of its potential use in economical and environmentally benign syntheses of amino compounds. With the aim of providing a comprehensive overview of this field, which is of interest to both the synthetic organic and inorganic communities, this paper reviews the status quo of $\mathrm{C}-\mathrm{H}$ amination chemistry by iron-imido/nitrene intermediates, as well as by well-defined iron-imido/nitrene compounds, with special emphasis on their structure/reactivity correlations. Achievements, problems, and perspectives in this growing field are discussed.
\end{abstract}

iron, nitrene, imido, $\mathrm{C}-\mathrm{H}$ amination, $\mathrm{C}-\mathrm{H}$ activation

Citation: Zhang L, Deng L. C-H bond amination by iron-imido/nitrene species. Chin Sci Bull, 2012, 57: 2352-2360, doi: 10.1007/s11434-012-5151-x

Nitrene insertion into $\mathrm{C}-\mathrm{H}$ bonds is a highly attractive synthetic strategy for the introduction of amino groups into organic molecules. This $\mathrm{C}-\mathrm{H}$ bond amination method can ideally install an amino group in an organic skeleton in a single step, avoiding tedious multiple-step functional group transformations [1]. Since nitrenes are very reactive intermediates, reactions using in-situ-generated free nitrenes generally display low chemo- and regio-selectivity [2,3]. Hence, controlling the reactivity of nitrene species is the primary issue which has to be addressed to enable them to be used in synthetic chemistry. To tackle this problem, efforts have been expended mainly on two aspects: (1) tailoring the reactivity of nitrene species by modifying the steric and electronic properties of their substituents, and (2) controlling the reactivity with the assistance of transition metals, possibly via transition-metal-imido/nitrene intermediates. The cumulated knowledge on these two points has led to the emergence of rhodium-, ruthenium-, copper-, iron-, and manganese-catalyzed $\mathrm{C}-\mathrm{H}$ amination methods with azides, haloamines, and iminoiodanes as the nitrene precursors, and elegant $\mathrm{Rh}_{2}(\mathrm{OAc})_{4}$-catalyzed intramolecular $\mathrm{C}-\mathrm{H}$ bond amination reactions have been applied to the total syntheses

*Corresponding author (email: deng@ sioc.ac.cn) of complex molecules [4].

Understanding the geometric and electronic properties of transition-metal-imido/nitrene species is beneficial in the design of new metal-catalyzed $\mathrm{C}-\mathrm{H}$ amination reactions with high efficiencies and selectivities [5-7]. Interestingly, although development of rhodium- and copper-catalyzed $\mathrm{C}-\mathrm{H}$ amination methods has been the most successful, the structural and chemical properties of rhodium- and copper-imido/nitrene complexes are virtually unknown [8]. In sharp contrast, a plethora of iron-imido/nitrene complexes, spanning a wide range of nuclearities and oxidation states, have been reported and their structural and electronic properties have been extensively investigated [9], but little work has been done on their $\mathrm{C}-\mathrm{H}$ activation activities [10-12]. However, as a result of a surge of interest in iron catalysis in organic synthesis in recent years [13-22], the number of reports on iron-catalyzed $\mathrm{C}-\mathrm{H}$ bond amination reactions is now growing. Undoubtedly, considering their economical and environmentally benign features, ironcatalyzed $\mathrm{C}-\mathrm{H}$ aminations have good potential and deserve more attention. Encouraged by this, in this review we wish to summarize the progress in $\mathrm{C}-\mathrm{H}$ bond amination reactions using iron-imido/nitrene species, including both stoichiometric and catalytic systems. Because it is closely related, 
C-H bond activation using iron-imido/nitrene species without further $\mathrm{C}-\mathrm{N}$ bond formation has also been included. Other related iron-catalyzed $\mathrm{C}-\mathrm{H}$ amination reactions such as electrophilic $\alpha$-amination of carbonyl compounds $[23,24]$ or allylic amination via ene-reaction-like processes [25-34] are beyond the scope of this review.

\section{C-H amination with iron-imido porphyrin and phthalocyanine species}

Recognition of the epoxidation and $\mathrm{C}-\mathrm{H}$ bond hydroxylation reactivities of porphyrin-based iron-oxo $(\mathrm{Fe}=\mathrm{O})$ species in cytochrome P-450s and related biomimetic systems stimulated interest in their isoelectronic analogs, iron-imido species $(\mathrm{Fe}=\mathrm{NR})$, in the early $1980 \mathrm{~s}$. The seminal work was done by Breslow and Gellman [35,36]. In 1982, they reported that both $\mathrm{Fe}(\mathrm{TPP}) \mathrm{Cl}$ and $\mathrm{Mn}(\mathrm{TPP}) \mathrm{Cl}$ (TPP = tetraphenylporphyrin) could promote tosylamidation of cyclohexane in a $1: 1(\mathrm{v} / \mathrm{v})$ dichloromethane-cyclohexane solution with tosyliminoiodane as the nitrogen source. With $\mathrm{Fe}$ (TPP) $\mathrm{Cl}$, the reaction gave $N$-cyclohexyltoluene- $p$-sulfonamide in $62 \%$ yield, based on the iron porphyrin, and $3.1 \%$ based on the iodo compound (Scheme 1) [35]. In later work, they found that the iron-catalyzed intramolecular $\mathrm{C}-\mathrm{H}$ amination reaction proceeded with improved efficiency. The substrate 2,5-diisopropylbezenenesulfoiminoiodane was converted to the $\mathrm{C}-\mathrm{H}$ insertion product in $77 \%$ yield using $5 \mathrm{~mol} \%$ of $\mathrm{Fe}(\mathrm{TPP}) \mathrm{Cl}$ as the catalyst, and in $42 \%$ yield using $\left[\mathrm{Fe}(\right.$ cyclam $\left.) \mathrm{Cl}_{2}\right] \mathrm{Cl}$ (cyclam $=1,4,8,11$-tetraazacyclotetradecane) as the catalyst (Scheme 2) [36]. In addition to the $\mathrm{C}-\mathrm{H}$ amination product, a small amount of dehydrogenation product was also observed. Since controlled experiments indicated that iminoiodane is stable in acetonitrile, iron-nitrene insertion into the $\mathrm{C}-\mathrm{H}$ bond was proposed for this $\mathrm{C}-\mathrm{H}$ amination reaction. In line with these observations, it was reported that cytochrome-P450 isoenzymes purified from rabbit liver microsomes catalyzed both the intra- and inter-molecular $\mathrm{C}-\mathrm{H}$ amination reactions [37]. Notably, as a result of the fast hydrolysis of possible transient iron-nitrene species, the enzymatic reaction gave cyclohexanol as the main product and the amination product in small quantities.

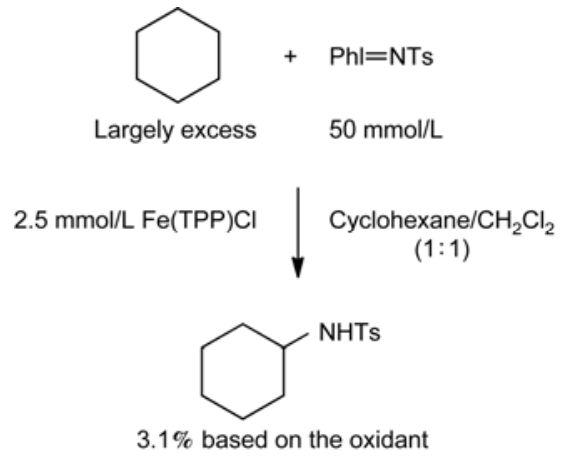

Scheme $1 \mathrm{Fe}(\mathrm{TPP}) \mathrm{Cl}$-mediated intermolecular $\mathrm{C}-\mathrm{H}$ amidation.
Parallel to these studies, Mansuy and co-workers [38] investigated the intermolecular amination reactions of alkanes with tosyliminoiodane with different iron porphyrins as catalysts. Although the yields of $\mathrm{C}-\mathrm{H}$ amination products were not high, the study showed that the use of cationic porphyrin complexes, $\mathrm{Fe}(\mathrm{TPP})\left(\mathrm{CF}_{3} \mathrm{SO}_{3}\right)$ and $\mathrm{Fe}(\mathrm{TDCPP})\left(\mathrm{CF}_{3} \mathrm{SO}_{3}\right)$ (TDCPP $=$ tetra-2,6-dichlorophenylporphyrin), as catalysts could increase the yields by a factor of 2 to 3 compared with the reactions using $\mathrm{Fe}(\mathrm{TPP}) \mathrm{Cl}$ as the catalyst. More interestingly, the amination of $n$-heptane was found to be regioselective and mainly afforded, with all three iron porphyrins, 2-tosylaminoheptane (Scheme 3). The author ascribed this particular regioselectivity to the joint steric effect of the ortho substituents of the porphyrin's meso-aryl groups and the tosyl group of the imido ligand.

Since these pioneering studies in the 1980s, there has been little further exploration of iron-porphyrin-catalyzed $\mathrm{C}-\mathrm{H}$ aminations. Only two related examples have appeared in the literature. In one study, Zhou and co-workers [39] reported that substituted iron(III) phthalocyanines, which are structurally similar to iron porphyrins, could catalyze nitrene transfer reactions of tosyliminoiodane with adamantane and ethylbenzene derivatives to afford amination products in decent yields (Table 1). These nitrene insertion reactions<smiles>CCCc1ccc(Br)c(S(=O)(=O)Nc2ccccc2)c1</smiles>
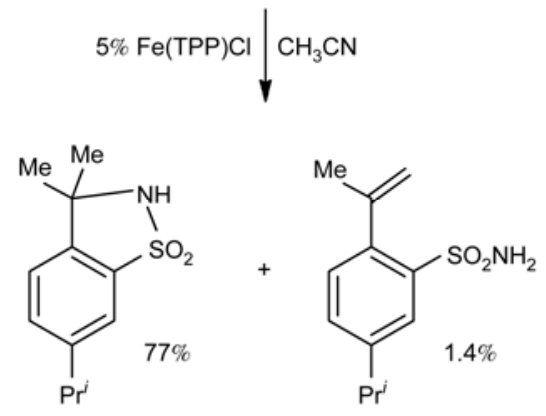

Scheme $2 \mathrm{Fe}$ (TPP)Cl-mediated intramolecular $\mathrm{C}-\mathrm{H}$ amidation.

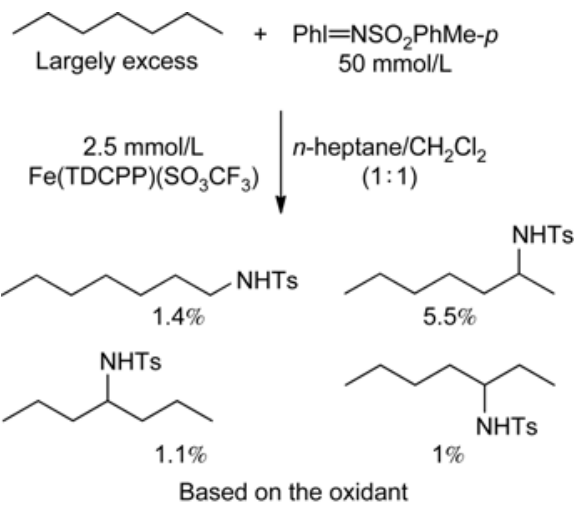

Scheme 3 [Fe(TDCPP) $]^{+}$-catalyzed C-H amidation of $n$-heptane. 
Table 1 Amidation of benzylic C-H bonds catalyzed by iron(III) phthalocyanines $^{\text {a) }}$

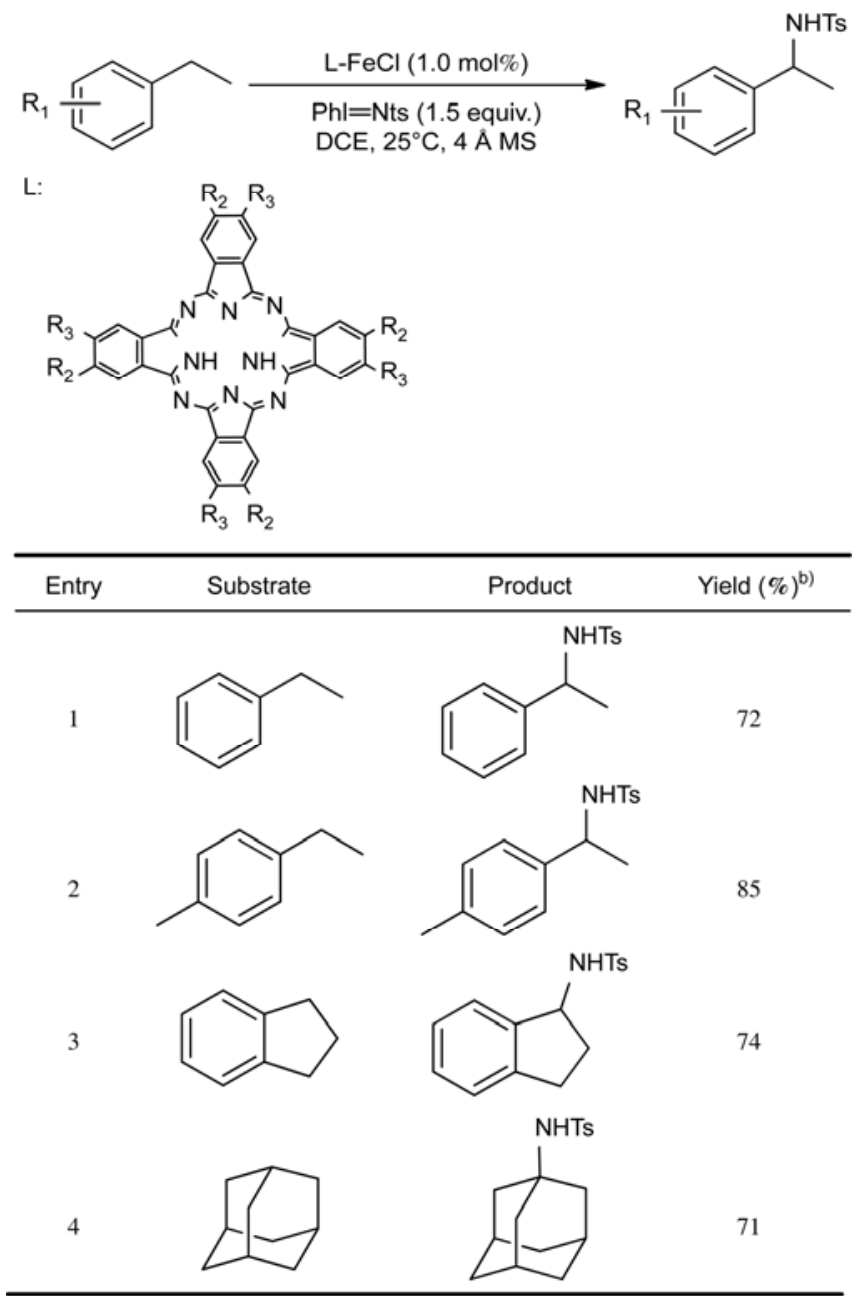

a) Reactions were performed with a cat: substrate: $\mathrm{Phl}=\mathrm{NT}$ molar ration of $1: 100: 150 ; b)$ isolated yield based on substrates used. took place preferentially at electron-rich $\mathrm{C}-\mathrm{H}$ bonds, as 1-tosylaminoadamantane and benzyl-substituted amino products were exclusively obtained. In another study, Che et al. [40] systematically investigated the catalytic performance of a perfluorinated porphyrin, $\mathrm{Fe}\left(\mathrm{F}_{20}-\mathrm{TPP}\right) \mathrm{Cl}$, in nitrene transformation reactions. The catalyst exhibited high efficiency in catalyzing aziridation of alkenes, imidation of sulfides, and allylic amination of $\alpha$-methylstyrenes with sulfonyl azides as the nitrogen source, but was unviable in $\mathrm{C}-\mathrm{H}$ bond aminations. However, changing the nitrogen source from sulfonyl azides to 4-nitrophenyl azide triggered intermolecular $\mathrm{C}-\mathrm{H}$ amination reactions. As shown in Table 2 , with $\mathrm{Fe}\left(\mathrm{F}_{20}-\mathrm{TPP}\right) \mathrm{Cl}$ as the catalyst, not only the benzylic $\mathrm{C}-\mathrm{H}$ bonds but also the stronger $\mathrm{C}-\mathrm{H}$ bonds in cycloheptane, cyclooctane, and adamantane could be successfully aminated by 4-nitrophenyl azide in moderate to good yields. These results in combination with Mansuy's findings [38] demonstrated that the $\mathrm{C}-\mathrm{H}$ activation reactivity of porphyrin-based iron-imido/nitrene species could be tuned by adjusting the steric and electronic natures of the substituents on either the porphyrin ligand or the imido moiety.

It should be noted that although imido-bound iron-porphyrin species were generally proposed in the $\mathrm{C}-\mathrm{H}$ amination reactions discussed above, knowledge of their exact molecular identity is ambiguous. The only structurally characterized imido/nitrene iron-porphyrin compound is $\left[\mathrm{Fe}(\mathrm{TpClPP})\left(\mathrm{NNC}_{9} \mathrm{H}_{18}\right)\right]$, prepared by the reaction of $\mathrm{Fe}(\mathrm{TpClPP}) \mathrm{Cl}$ (TpCIPP = tetrakis( $p$-chlorophenyl)porphyrin) with 1-amino-2,2,6,6-tetramethylpiperidine under oxidizing conditions (Figure 1(a)) [41,42]. This five-coordinated compound possesses a linear $\mathrm{Fe}-\mathrm{N}-\mathrm{N}$ alignment and a short $\mathrm{Fe}-\mathrm{N}$ (axial) bond (1.809(4) $\AA$ ), indicating multiple bond character of the $\mathrm{Fe}-\mathrm{N}$ (axial) bond. Magnetic susceptibility measurements and Mössbauer studies suggested a high-spin

Table 2 Iron-porphyrin-catalyzed C-H bond amination with 4-nitrophenyl azide ${ }^{\text {a) }}$

\begin{tabular}{|c|c|c|c|c|c|c|c|}
\hline Entry & Substrates & Products & Yield $(\%)^{\mathrm{b})}$ & Entry & Substrates & Products & Yield $(\%)^{\mathrm{b})}$ \\
\hline 1 & & & 71 & 5 & & & 78 \\
\hline 2 & & & 73 & 6 & & & 65 \\
\hline 3 & & & 72 & 7 & & & 64 \\
\hline 4 & & & 80 & 8 & & & 68 \\
\hline
\end{tabular}

a) Reactions were performed with alkane $(2.00 \mathrm{mmol})$, 4-nitrophenylazide $(0.20 \mathrm{mmol})$, [Fe $\mathrm{Fe}^{\mathrm{III}}\left(\mathrm{F}_{20}\right.$-tpp $\left.) \mathrm{Cl}\right](0.004 \mathrm{mmol})$, and $4 \AA$ molecular sieves $(60 \mathrm{mg})$ in anhydrous $\mathrm{ClCH}_{2} \mathrm{CH}_{2} \mathrm{Cl}(1 \mathrm{~mL})$ under $\mathrm{N}_{2}$; b) yield of isolated product based on conversion. 


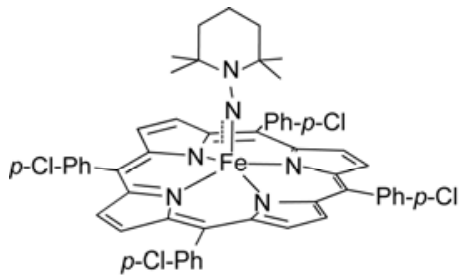

(a)

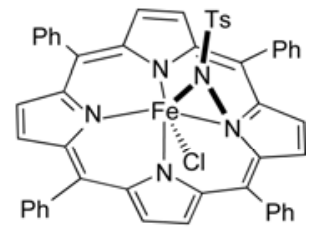

(b)

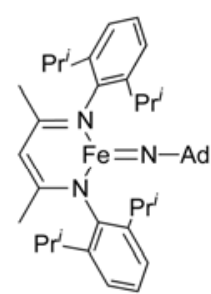

(c)

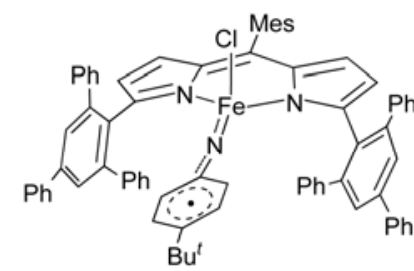

(d)
Figure 1 Examples of iron-imido complexes.

$(S=2)$ ferrous state for this compound. Hence, the $\mathrm{NNC}_{9} \mathrm{H}_{18}$ fragment could be formally viewed as a neutral nitrene ligand. However, attempts to prepare iron-porphyrin-nitrene complexes by a nitrene transfer reaction between iron(III) porphyrin chlorides and $\mathrm{PhI}=\mathrm{NTs}$ in $\mathrm{CH}_{2} \mathrm{Cl}_{2}$, led to the isolation of an iron(III) complex with a tosylnitrene inserted into an Fe-N(TPP) bond (Figure 1(b)) [43]. The formation of this unusual nitrene insertion product, rather than $\mathrm{Fe}(\mathrm{TPP})(\mathrm{NTs})$, highlighted the high reactivity of terminally bonded iron-porphyrin-imido/nitrene species.

Theoretical studies of iron-porphyrin-nitrene/imido systems relevant to $\mathrm{C}-\mathrm{H}$ activation are also rare. Ghosh et al. [44] have reported density functional theory studies on the five-coordinated $\mathrm{Fe}^{\mathrm{IV}}$ (porphyrin)(NH) species. The calculations revealed that this species has a short $\mathrm{Fe}-\mathrm{NH}$ separation of $1.698 \AA$, a triplet ground state, and a large spin-distribution on its terminal bonded NH moiety. Density functional theory calculations on six-coordinated azocompound I species, $\mathrm{Fe}$ (porphyrin)(NR)(X) $\left(\mathrm{R}=\mathrm{SO}_{2} \mathrm{Me}, \mathrm{H} ; \mathrm{X}=\right.$ $\mathrm{Cl}, \mathrm{SH})$, were performed by Shaik and co-workers [45]. The study showed that all four species possess degenerate quartet and doublet states with two unpaired electrons on the $\mathrm{Fe}=\mathrm{NR}$ moiety, ferromagnetically and antiferromagnetically coupled to an electron on the porphyrin part. Similar to the five-coordinated species, large spin-densities on the terminal bonded nitrogen atoms were also observed for these azo-compound I species. The calculated Fe-NR distances (1.789-1.857 $\AA$ ) varied with respect to the electronic nature of the R group: an electron-withdrawing $\mathrm{R}$ group $\left(\mathrm{SO}_{2} \mathrm{Me}\right)$ generated longer $\mathrm{Fe}=\mathrm{N}$ bonds than those obtained with an electron-releasing $\mathrm{R}$ group. Based on analysis of the energy profiles and structures of the critical species in the reactions between $\mathrm{Fe}$ (porphyrin)(NR)(X) and propene, the study further predicted that electron-releasing $\mathrm{R}$ substituents of small bulk would be powerful aziridation reagents, whereas sterically bulky electron-withdrawing $\mathrm{R}$ groups would prefer $\mathrm{C}-\mathrm{H}$ amination. Unfortunately, this prediction is not in line with the experimental results reported by Che et al. [40].

\section{C-H amination with non-heme-type iron- imido species}

At almost the same time as Breslow was investigating iron-porphyrin-mediated $\mathrm{C}-\mathrm{H}$ amination with iminoiodane, Motherwell et al. [46] were using a combination of $\mathrm{FeCl}_{2}$ and chloramine-T to functionalize hydrocarbons such as adamantane, cyclohexene, and naphthalene. These stoichiometric reactions did afford net $\mathrm{C}-\mathrm{H}$ amination products, but the authors suggested that because chlorination intermediates had been observed, the $\mathrm{FeCl}_{2}$ /chloramine- $\mathrm{T}$ complex functions in the first instance as a powerful chlorinating reagent to afford chloro compounds, which are subsequently displaced by the nitrogen nucleophile. Relevant to this study, $\mathrm{Fu}$ and co-workers [47] recently achieved the $\mathrm{FeCl}_{2}$-catalyzed amination of benzylic $\mathrm{C}-\mathrm{H}$ bonds with $\mathrm{N}$-bromosulfonamide generated by interaction of $\mathrm{N}$-bromosuccinimide with sulfonylamide. Considering the analogy between these two systems, C-H chlorination followed by amide substitution, rather than direct $\mathrm{C}-\mathrm{H}$ amintion by iron-imido species, seems a more reasonable mechanism for this iron-catalyzed benzylic $\mathrm{C}-\mathrm{H}$ amination reaction.

The capability of non-heme iron-imido species to facilitate $\mathrm{C}-\mathrm{H}$ activation was first revealed by Que et al. [48] in the reaction of $\left[(6-\mathrm{PhTPA}) \mathrm{Fe}(\mathrm{NCMe})_{2}\right]\left[\mathrm{ClO}_{4}\right]_{2}$ with tosyliminoiodane (Scheme 4). The reaction gave an intramolecular aromatic $\mathrm{C}-\mathrm{H}$ amination product, an iron(III)-anilido compound, which was thought to come from electrophilic attack on the appended phenyl ring by a reactive tosylimidoiron(IV) intermediate followed by dehydrogenative oxidation with tosyliminoiodane. Evidence suggesting the involvement of a $\sigma$-complex was obtained from isotope labeling experiments. Similarly, a diiron complex was also found to be amenable to aromatic $\mathrm{C}-\mathrm{H}$ amination when treated with tosyliminoiodane (Scheme 5) [49]. Interestingly, although the dinuclear complex showed a weak ability to mediate oxygen transfer, it was very efficient in promoting nitrene transfer reactions, and even gave significant formation of double aromatic $\mathrm{C}-\mathrm{H}$ amination products. The involvement of an iron(IV)-imido intermediate was proposed for this diiron-mediated $\mathrm{C}-\mathrm{H}$ amination reaction.

Elegant transformations of iron-catalyzed aromatic $\mathrm{C}-\mathrm{H}$ amination reactions have been developed. Zheng and co-workers [50] found that $\mathrm{FeCl}_{2}$ could catalyze the ring opening of phenyl-substituted $2 \mathrm{H}$-azirines to afford 2,3-disubstituted indoles in moderate to good yields (Scheme 6). The intramolecular interaction between the vinyl-nitreneiron species, formed by $\mathrm{FeCl}_{2}$-promoted ring opening of $2 \mathrm{H}$-azirines, and the aromatic $\mathrm{C}-\mathrm{H}$ bond at the ortho position was proposed as the $\mathrm{C}-\mathrm{N}$ bond formation step. Notably, this iron-catalyzed aromatic $\mathrm{C}-\mathrm{H}$ amination reaction displayed a similar kinetic isotope effect of 1.3 as that of the 


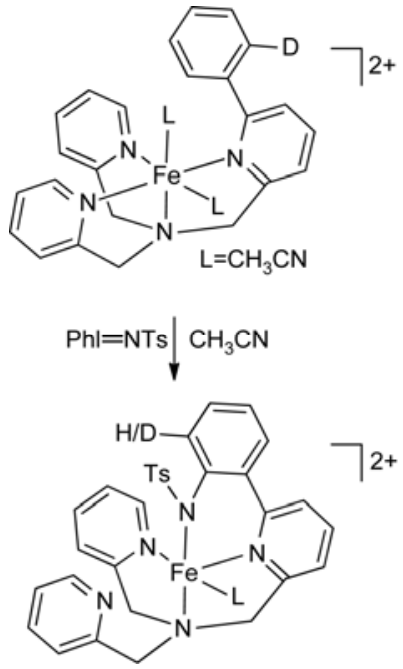

Scheme 4 Aromatic C-H amination reaction within a TPA-iron complex.
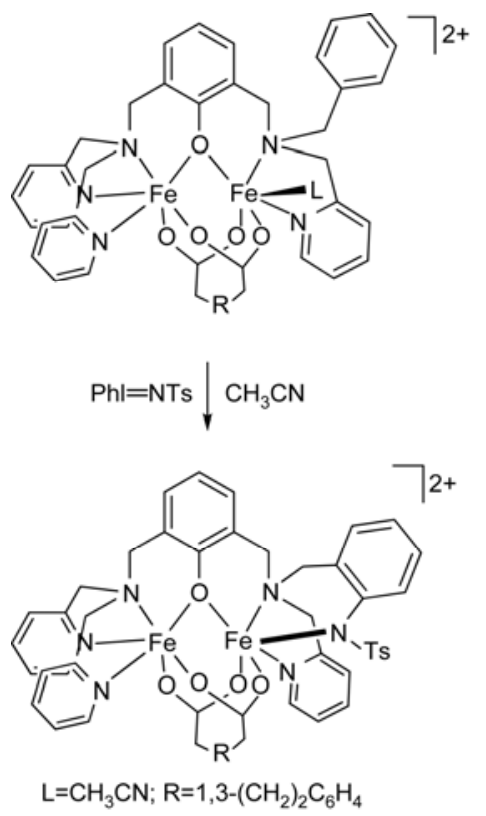

Scheme 5 Aromatic C-H amination reaction within a diiron complex.

stoichiometric C-H amination reaction of Que's mononuclear iron complex, indicating a common 1,2-hydrogen shift step in their mechanisms. An $\mathrm{Fe}(\mathrm{OTf})_{2}$-catalyzed ring-closure reaction of aryl azidoacrylate to give indoles has been developed by Bonnamour and Bolm (Scheme 7) [51]. Since organic azides were known to react with low-valent iron complexes to afford iron-imido complexes [9], this intramolecular $\mathrm{C}-\mathrm{H}$ amination reaction might also proceed via an iron-imido intermediate.

In addition to aromatic $\mathrm{C}-\mathrm{H}$ bond activation, non-hemetype iron-imido intermediates presumably were also able to perform $\mathrm{C}\left(\mathrm{sp}^{3}\right)-\mathrm{H}$ bond activation. In an attempt to prepare iron-imido complexes by the reaction of a trigonal monopyramidal iron(II) complex with $p$-tolyl azide, Borovik et al.

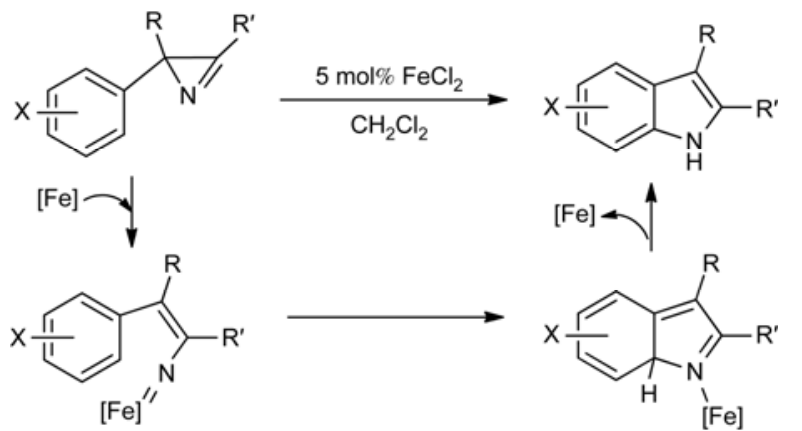

Scheme 6 Formation of indoles via $\mathrm{FeCl}_{2}$-catalyzed ring opening of phenyl-substituted $2 \mathrm{H}$-azirine.

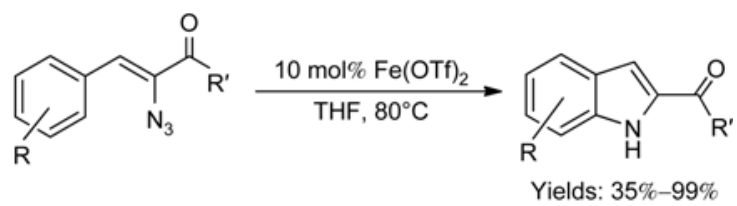

Scheme $7 \mathrm{Fe}(\mathrm{OTf})_{2}$-catalyzed ring-closure reaction of aryl azidoacrylate.

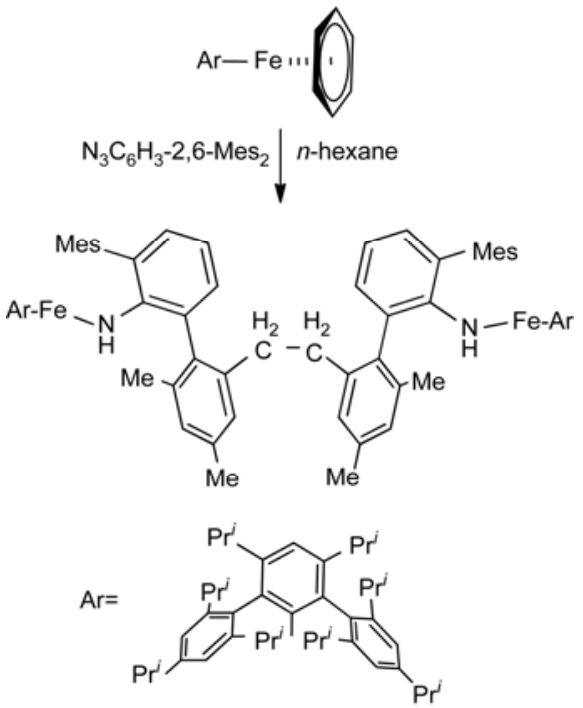

Scheme 8 Iron-mediated sequential $\mathrm{C}-\mathrm{H}$ activation and $\mathrm{C}-\mathrm{C}$ bond formation.

[52] found that the initially formed product, presumably an iron(IV)-imido species, was quite unstable and could abstract hydrogen atoms from 9,10-dihydroanthracene (DHA) to afford an iron(III)-amido compound and anthracene. Later, Peters et al. [53] observed the hydrogen atom abstraction (HAA) reactivity of an iron(III)-imido intermediate toward DHA, in which the iron(III) complex was reduced to an iron(II)-anilido compound. Intramolecular HAA within an iron(III)-imido intermediate was also suggested by Power et al. as the $\mathrm{C}-\mathrm{H}$ activation step in the reaction of an iron(I) compound with a bulky azide (Scheme 8) [54].

Few of the well-characterized iron-imido complexes exhibit $\mathrm{C}-\mathrm{H}$ activation reactivity. The three-coordinated iron(III)- 
imido complex [(nacnac)FeNAd] $($ nacnac = diketimine; $\mathrm{Ad}$ = adamantyl) (Chart 1(c)) reported by the Holland group [55-58] represents the first example of this type. The imido compound was prepared by the reaction of $\left[(\right.$ nacnac $) \mathrm{Fe}\left(\mathrm{N}_{2}\right)$ $\mathrm{Fe}($ nacnac)] with adamantyl azide in tetrahydrofuran. Although the good stability of this three-coordinated complex at $-45^{\circ} \mathrm{C}$ enabled its full characterization by crystallography, NMR, EXAFS, EPR, Mössbauer, and magnetic susceptibility, on addition of $p$-tert-butylpyridine ( $t$-BuPy) to a solution of the compound, an intramolecular $\mathrm{C}-\mathrm{H}$ activation reaction of the isopropyl groups on the nacnac ligand occurred and resulted in the formation of a unique high-spin iron(III)-adamantylamido complex (Scheme 9) [55]. The addition of hydrocarbons with weak $\mathrm{C}-\mathrm{H}$ bonds, such as 1,4-dihydronaphthalene, 1,4-cyclohexadiene, indene, and cyclopentadiene, could prevent intramolecular attack on the diketiminate ligand and facilitate intermolecular HAA reactions, affording the iron(II)-amido compound [(nacnac) $\mathrm{Fe}(\mathrm{NHAd})(t$-BuPy)] (Scheme 9) [56,57]. Both equilibrium and kinetic studies suggest that the four-coordinated imido intermediate (nacnac)Fe(NAd)( $t$-BuPy) is the HAA-performing species.

To clarify the factors effecting the magnified $\mathrm{C}-\mathrm{H}$ activation reactivity of this four-coordinated species, theoretical calculations on the electronic structures of the three- and four-coordinated imido species as well as their HAA reactions toward 1,4-cyclohexadiene were performed [56]. The calculations revealed that although in (nacnac)Fe(NAd)( $t$ -
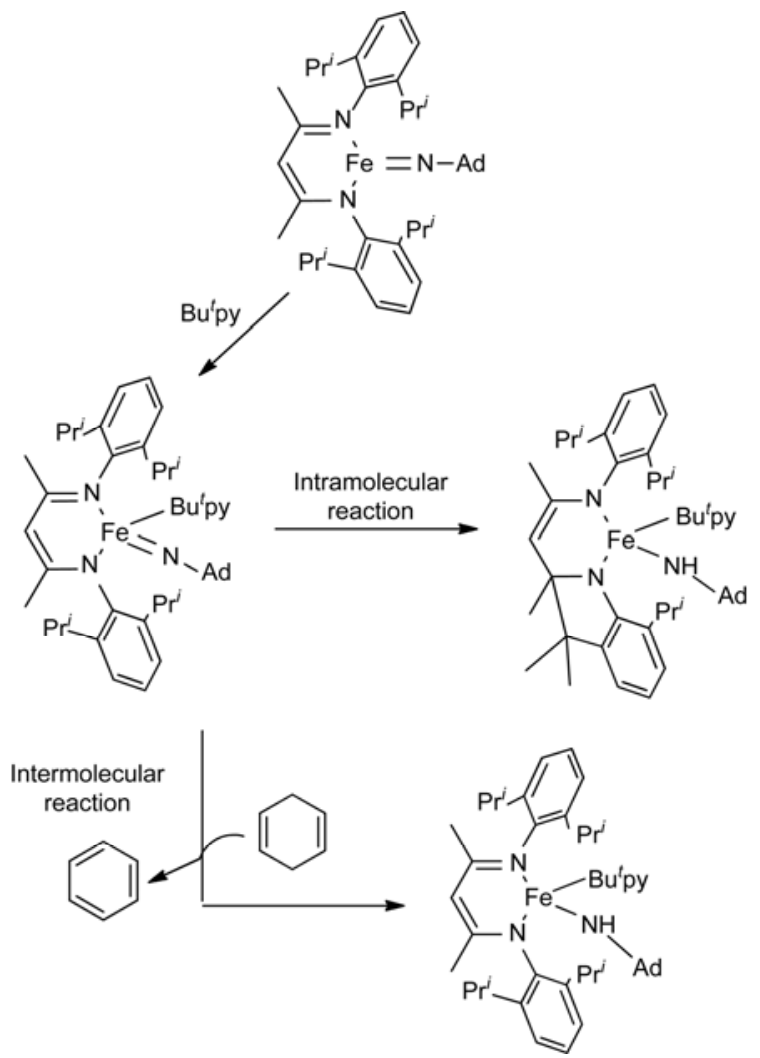

Scheme 9 Hydrogen atom abstraction reactivity of (nacnac)FeNAd.
BuPy) the quartet and sextet states have similar energies (less than $2 \mathrm{kcal} / \mathrm{mol}$ ), whereas those of (nacnac)Fe(NAd) differ significantly $(15 \mathrm{kcal} / \mathrm{mol})$, the calculated energies of the lowest transition state for HAA by the four-coordinated species do not differ significantly for the two spin states. The calculation results therefore do not support the idea of spin-state-dependent reactivity in this iron system. The longer $\mathrm{Fe}=\mathrm{N}$ bond and more basic imido nitrogen atom on the four-coordinated iron-imido compound, as well as stabilization of the resultant iron(II)-amido product on coordination with pyridine, were thought to be more important factors in accounting for the potency of (nacnac)Fe(NAd)( $t$ BuPy) toward HAA reactions.

A genuine example of an iron-imido compound capable of performing $\mathrm{C}-\mathrm{H}$ bond amination emerged very recently (Figure 1(d)). During their investigations of iron-dipyrromethene complexes as heme surrogates, Betley et al. [59] reported in 2009 that iron(II) chloride bearing a mesitylsubstituted dipyrromethene ligand could react with organic azides to give facial intramolecular amination products (Scheme 10). An iron-imido intermediate was proposed for the intramolecular $\mathrm{C}-\mathrm{H}$ amination reaction but has not been isolated. Subsequently, the group modified the dipyrromethene ligand by introducing other bulky substituents with stronger $\mathrm{C}-\mathrm{H}$ bonds, such as tert-butyl, adamantyl, and 2,4,6-triphenylphenyl, on the ligand scaffold. The modification turned out to be effective as both the tert-butyl- and adamantyl-substituted iron(II) complexes could catalyze intermolecular $\mathrm{C}-\mathrm{H}$ amination reactions between toluene and adamantyl azide, giving benzyladamantylamine in high yields (Scheme 11) [60]. More significantly, the sterically hindered aryl ligand enabled the synthesis of a stable four-coordinated iron-imido complex (Figure 1(d)), which could perform not only HAA when treated with 1,4-cyclohexediene, but also benzylic $\mathrm{C}-\mathrm{H}$ bond amination by interaction with toluene.

The four-coordinated complex displayed a kinetic isotope effect of 24 in its $\mathrm{C}-\mathrm{H}$ activation reactions; this is consistent with the values obtained in catalytic reactions using its tert-butyl- and adamantyl-substituted analogs as the catalyst and suggests that imido-iron species are viable intermediates in the $\mathrm{C}-\mathrm{H}$ activation reactions [60]. Spectroscopic, magnetic, and computational studies revealed that the electronic structure of this iron-imido complex could be interpreted as an imido radical anion strongly coupled to

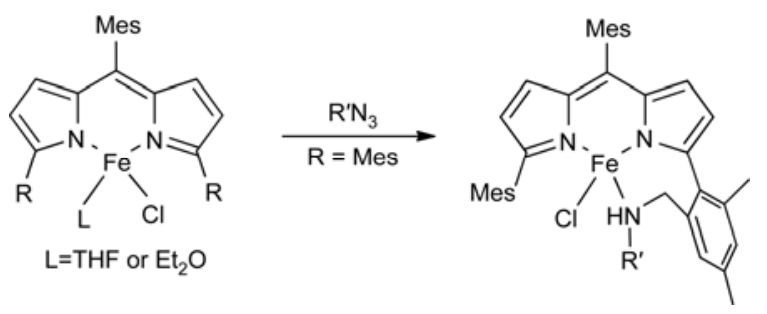

Scheme 10 Intramolecular $\mathrm{C}-\mathrm{H}$ amination within iron-dipyrromethene complexes. 
high-spin iron(III), (L)Fe ${ }^{\mathrm{III}} \mathrm{Cl}\left({ }^{-} \mathrm{NR}\right)$, which might account for its unusual $\mathrm{C}-\mathrm{H}$ activation reactivity. The presence of an aryl-delocalized radical was also indicated by the elongated Fe-NAr bond (1.768(2) $\AA$ ) and the $\mathrm{N}-\mathrm{C}, \mathrm{C}-\mathrm{C}$ bond-length pattern within the nitrene moiety.

Some examples of non-heme-type iron complexes catalyzing $\mathrm{C}-\mathrm{H}$ amination reactions with iminoiodanes as the nitrene source appear in the literature. Che group [61] reported that intramolecular $\mathrm{C}-\mathrm{H}$ aminations of sulfamate esters at the benzylic position could be achieved in good yields using $\left[\mathrm{Fe}\left(\mathrm{Cl}_{3} \text { terpy }\right)_{2}\right]^{2+}\left(\mathrm{Cl}_{3}\right.$ terpy $=4,4^{\prime}, 4^{\prime \prime}$-trichloroterpyridine) as a catalyst (Scheme 12). The imido intermediate $\left[\mathrm{Fe}\left(\mathrm{Cl}_{3} \text { terpy }\right)_{2}(\mathrm{NTs})\right]^{2+}$ has been proposed and was supported by ESI-MS studies. Chan et al. [62] recently described a method for the amidation of aryl and alkyl aldehydes by iminoiodanes with $\left[\mathrm{Fe}(\mathrm{py})_{4} \mathrm{Cl}_{2}\right]$ as a precatalyst. Based on kinetic studies, the absence of significant electronic effects in the amidation process when using different para-substituted phenyl aldehydes, and a kinetic isotope effect of 4.4 for $\mathrm{PhCHO} / \mathrm{PhCDO}$, the authors proposed a HAT/radical rebound pathway for the formylic $\mathrm{C}-\mathrm{H}$ amidation reaction. Similarly, $\left[\mathrm{Fe}(\text { terpy })_{2}\right]^{2+}$ was also found to be effective as a catalyst in nitrene insertion reactions of aldehydes with tosyliminoiodane, and an iron-imido intermediate, $\left[\mathrm{Fe}(\text { terpy })_{2^{-}}\right.$ $(\mathrm{NTs})]^{2+}$, has been proposed, based on ESI-MS studies [63].
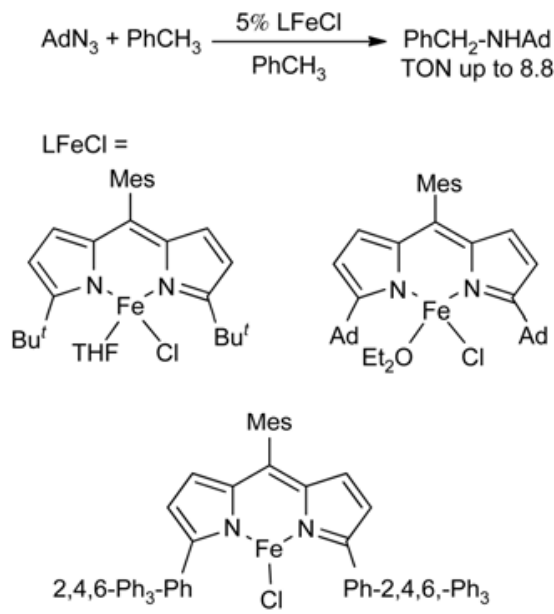

Scheme 11 Iron-dipyrromethene-catalyzed $\mathrm{C}-\mathrm{H}$ amination between toluene and adamantyl azide.
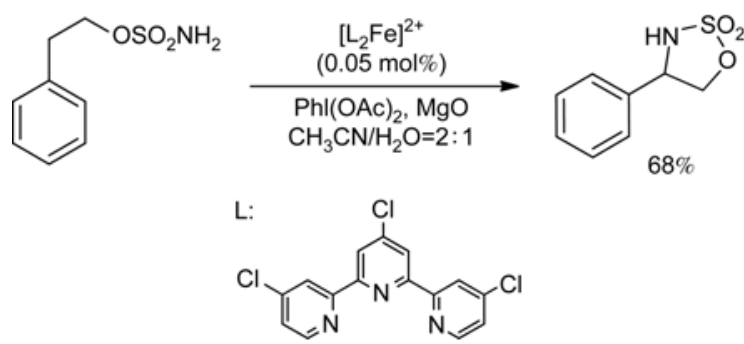

Scheme $12\left[\mathrm{Fe}\left(\mathrm{Cl}_{3} \text { terpy }\right)_{2}\right]^{2+}$-catalyzed intramolecular amidation of sulfamate esters.

\section{Summary and perspective}

As stated at the beginning of this review, iron-catalyzed $\mathrm{C}-\mathrm{H}$ amination reactions stand out among transition-metalcatalyzed amination methods in terms of economy and environmental friendliness. With continuing research in this field, knowledge of the structure/reactivity relationships of iron-imido species has been accumulated and new methods, based on iron-catalyzed $\mathrm{C}-\mathrm{H}$ amination, for the synthesis of amino and amido compounds are emerging. The aforementioned studies have demonstrated that the electronic structure of the Fe-NR moiety could be affected by the oxidation state of the iron center, the electronic and steric properties of the $\mathrm{R}$ group, and the ancillary ligand. As in iron-oxo chemistry, the radical character of the imido moiety has been recognized as one of the key factors governing its $\mathrm{C}-\mathrm{H}$ activation reactivity since both theoretical and experimental evidence have shown the electronic structure of a radical anion ( $\left.{ }^{-} \mathrm{NR}\right)$ for the NR group in some iron-nitrene/imido species. A mechanism involving HAA from $\mathrm{C}-\mathrm{H}$ bonds by iron-imido species followed by radical $\left(\mathrm{R}^{*}\right)$ rebound to the iron-amido moiety is now a generally recognized pathway for iron-catalyzed $\mathrm{C}\left(\mathrm{sp}^{3}\right)-\mathrm{H}$ amination reactions (Scheme 13). However, controlling the HAA reactivity of the ironimido species and facilitating efficient $\mathrm{C}-\mathrm{N}$ bond formation after $\mathrm{C}-\mathrm{H}$ activation upon modification of its ligand environment or of the substituents on the $\mathrm{N}$ (imido) atom are still open questions worth further exploration. The known ironcatalyzed $\mathrm{C}-\mathrm{H}$ amination reactions are viable for $\mathrm{C}-\mathrm{H}$ bonds at benzylic or allylic positions and many of the reactions take place in intramolecular versions. In contrast, methods dealing with stronger $\mathrm{C}-\mathrm{H}$ bonds and/or intermolecular $\mathrm{C}-\mathrm{H}$ aminations are rare. Extension of the substrate scope to stronger aliphatic $\mathrm{C}-\mathrm{H}$ bonds, as well as improving reaction efficiency and selectivity, are still challenges. Undoubtedly, a deeper knowledge of the structure/reactivity relationships of iron-imido species will help to address these problems and also help to understand the fundamentals of iron-catalyzed $\mathrm{C}-\mathrm{H}$ amination chemistry.

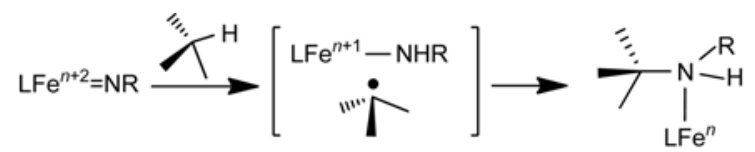

Scheme 13 Possible pathways for $\mathrm{C}\left(\mathrm{sp}^{3}\right)-\mathrm{H}$ amination via iron-imido intermediates.

This work was supported by the National Basic Research Program of China (2011CB808705) and the National Natural Science Foundation of China (21002114 and 20872168).

1 Ricci A. Amino Group Chemistry. Weinheim: Wiley-VCH, 2008

2 Moody C J. In Comprehensive Organic Synthesis. Oxford: Pergamon Press, 1992. 21-38 
3 Lowski W. Nitrene. New York: Interscience, 1970

4 Dauban P, Dodd R H. In Amino Group Chemistry. Weinheim: Wiley-VCH, 2008. 55-92

5 Nugent W A, Mayer J M. Metal-Ligand Multiple Bonds, the Chemistry of Transition Metal Complexes Containing Oxo, Nitrido, Imido, Alkylidyne Ligands. New York: Wiley, 1988

6 Eikey R A, Abu-Omar M M. Nitrido and imido transition metal complexes of groups 6-8. Coord Chem Rev, 2003, 243: 83-124

7 Li Y, Wong W T. Low valent transition metal clusters containing nitrene/imido ligands. Coord Chem Rev, 2003, 243: 191-212

8 Berry J F. Terminal nitrido and imido complexes of the late transition metals. Comments Inorg Chem, 2009, 30: 28-66

9 Mehn M P, Peters J C. Mid- to high-valent imido and nitrido complexes of iron. J Inorg Biochem, 2006, 100: 634-643

10 Sun S L, Li B J, Shi Z J. Direct C-H transformation via iron catalysis. Chem Rev, 2011, 111: 1293-1314

11 Che C M, Zhou C Y, Wong E L M. Catalysis by $\mathrm{Fe}=\mathrm{X}$ Complexes $\left(\mathrm{X}=\mathrm{N}-\mathrm{R}, \mathrm{CR}_{2}\right.$ ). Top Organomet Chem, 2011, 33: 111-138

12 Che C M, Lo V K Y, Zhou C Y, et al. Selective functionalisation of saturated $\mathrm{C}-\mathrm{H}$ bonds with metalloporphyrin catalysts. Chem Soc Rev, 2011, 40: 1950-1975

13 Plietker B. Iron Catalysis in Organic Chemistry. Weinheim: WileyVCH, 2008

14 Beller M, Bolm C. Transition Metals for Organic Synthesis. 2nd ed. Weinheim: Wiley-VCH, 2004

15 Jana R, Pathak T P, Sigma M S. Advances in transition metal (Pd,Ni, $\mathrm{Fe}$ )-catalyzed cross-coupling reactions using alkyl-organometallics as reaction partners. Chem Rev, 2011, 111: 1417-1492

16 Plietker B. Sustainability in catalysis-concept or contradiction? Synlett, 2010, 2049-2058

17 Liu L X. Recent use of iron catalysts in organic reactions. Curr Org Chem, 2010, 14: 1099-1126

18 Nakamura E, Yoshikai N. Low-valent iron-catalyzed C-C bond formation-addition, substitution, and $\mathrm{C}-\mathrm{H}$ bond activation. J Org Chem, 2010, 75: 6061-6067

19 Czaplik W M, Mayer M, Cvengros J, et al. Coming of age: Sustainable iron-catalyzed cross-coupling reactions. ChemSusChem, 2009, 2: 396-417

20 Enthaler S, Junge K, Beller M. Sustainable metal catalysis with iron: From rust to a rising star? Angew Chem Int Ed, 2008, 47: 3317-3321

21 Sherry B D, Fürstner A. The promise and challenge of iron-catalyzed cross coupling. Acc Chem Res, 2008, 41: 1500-1511

22 Correa A, García Mancheño O, Bolm C. Iron-catalysed carbonheteroatom and heteroatom-heteroatom bond forming processes. Chem Soc Rev, 2008, 37: 1108-1117

23 Greck C, Drouillat B, Thomassigny C. Asymmetric electrophilic $\alpha$-amination of carbonyl groups. Eur J Org Chem, 2004: 1377-1385

24 Janey J M. Recent advances in catalytic, enantioselective $\alpha$ aminations and $\alpha$ oxygenations of carbonyl compounds. Angew Chem Int Ed, 2005, 44: 4292-4300

25 Johannsen M, Jørgensen K A. Allylic amination. Chem Rev, 1998, 98: $1689-1708$

26 Srivastava R S, Khan M A, Nicholas K M. A novel intermediate in allylic amination catalyzed by iron salts. J Am Chem Soc, 1996, 118: 3311-3312

27 Srivastava R S, Nicholas K M. On the mechanism of allylic amination catalyzed by iron salts. J Am Chem Soc, 1997, 119: 3302-3310

28 Srivastava R S, Nicholas K M. Iron-catalyzed allylic amination by nitroorganics. Chem Commun, 1998, 2705-2706

29 Kolel-Veetil M, Khan M A, Nicholas K M. A cyclic carbamoyl complex is a resting state in allylic aminations catalyzed by $\left[\mathrm{Cp}{ }^{*} \mathrm{Fe}(\mathrm{CO})_{2}\right]_{2}$. Organometllics, 2000, 19: 3754-3756

30 Singh S, Nicholas K M. 2,4-Dinitrophenylhydroxylamine: An efficient and more general reagent for iron-catalyzed allylic amination. Synth Commun, 2001, 31: 3087-3097

31 Srivastava R S, Kolel-Veetil M, Nicholas K M. Photoassisted, ironcatalyzed allylic amination of olefins with nitroarenes. Tetrahedron Lett, 2002, 43: 931-934
32 Srivastava R S, Khan M A, Nicholas K M. Preparation and molecular structure of $\left[\left(\eta^{5}-\mathrm{C}_{5} \mathrm{H}_{5}\right) \mathrm{Fe}(\mathrm{CO})_{2}\left(\eta^{1}-\mathrm{PhNO}_{2}\right)\right] \mathrm{BF}_{4}$. Inorg Chim Acta, 2003, 349: 269-272

33 Stephens J C, Khan M A, Nicholas K M. Cyclopentadienyliron complexes of nitrosobenzene: Preparation, structure and reactivity with olefins. J Organomet Chem, 2005, 690: 4727-4733

34 Srivastava R S. Photo-induced iron-catalyzed allylic amination of unfunctionalized olefins with nitroarenes. Appl Organomet Chem, 2006, 20: 851-854

35 Breslow R B, Gellman S H. Tosylamidation of cyclohexane by a cytochrome P-450 model. J Chem Soc Chem Commun, 1982, 14001411

36 Breslow R B, Gellman S H. Intramolecular nitrene carbon-hydrogen insertions mediated by transition-metal complexes as nitrogen analogs of cytochrome P-450 reactions. J Am Chem Soc, 1983, 105: 6728-6729

37 Svastits E W, Dawson J H, Breslow R B, et al. Functionalized nitrogen atom transfer catalyzed by cytochrome P-450. J Am Chem Soc, 1985, 107: 6427-6428

38 Mahy J P, Bedi G, Battioni P, et al. Animation of alkanes catalyzed by iron and manganese-porphyrins: Particular selectivity for oxidations of linear alkanes. New J Chem, 1989, 13: 651-657

39 Yan S Y, Wang Y, Shu Y J, et al. Nitrene transfer reaction catalyzed by substituted metallophthalocyanines. J Mol Catal A-Chem, 2006, 248: $148-151$

40 Liu $\mathrm{Y}$, Che C M. $\left[\mathrm{Fe}^{\mathrm{III}}\left(\mathrm{F}_{20}-\mathrm{tpp}\right) \mathrm{Cl}\right]$ is an effective catalyst for nitrene transfer reactions and amination of saturated hydrocarbons with sulfonyl and aryl azides as nitrogen source under thermal and microwave-assisted conditions. Chem Eur J, 2010, 16: 10494-10501

41 Mansuy D, Battioni P, Mahy J P. Isolation of an iron-nitrene complex from the dioxygen- and iron porphyrin-dependent oxidation of a hydrazine. J Am Chem Soc, 1982, 104: 4487-4489

42 Mahy J P, Battioni P, Mansuy D, et al. Iron porphyrin-nitrene complexes: Preparation from 1,1-dialkylhydrazines. Electronic structure from NMR, Moessbauer, and magnetic susceptibility studies and crystal structure of the [tetrakis(p-chlorophenyl)porphyrinato][(2,2,6,6tetramethyl-1-piperidyl)nitrene]iron complex. J Am Chem Soc, 1984, 106: 1699-1706

43 Mahy J P, Battioni P, Bedi G, et al. Iron-porphyrin-nitrene complexes: Preparation, properties, and crystal structure of porphyrin-iron(III) complexes with a tosylnitrene inserted into an iron-nitrogen bond. Inorg Chem, 1988, 27: 353-359

44 Dey A, Ghosh A. "True" iron(V) and iron(VI) porphyrins: A first theoretical exploration. J Am Chem Soc, 2002, 124: 3206-3207

45 Moreau Y, Chen H, Derat E, et al. NR transfer reactivity of azocompound I of P450. How does the nitrogen substituent tune the reactivity of the species toward $\mathrm{C}-\mathrm{H}$ and $\mathrm{C}=\mathrm{C}$ activation? J Phys Chem B, 2007, 111: 10288-10299

46 Barton D H R, Hay-Motherwell R S, Motherwell W B. Functionalisation of saturated hydrocarbons. Part 1. Some reactions of a ferrous chloride-chloramine-T complex with hydrocarbons. J Chem Soc Perkin Trans 1, 1983: 445-451

47 Wang Z, Zhang Y, Fu H, et al. Efficient intermolecular iron-catalyzed amidation of $\mathrm{C}-\mathrm{H}$ bonds in the presence of $\mathrm{N}$-bromosuccinimide. Org Lett, 2008, 10: 1863-1866

48 Jensen M P, Mehn M P, Que Jr L. Intramolecular aromatic amination through iron-mediated nitrene transfer. Angew Chem Int Ed, 2003, 42: 4357-4360

49 Avenier F, Gouré E, Dubourdeaux P, et al. Multiple aromatic amination mediated by a diiron complex. Angew Chem Int Ed, 2008, 47: 715-717

50 Jana S, Clements M D, Sharp B K, et al. Fe(II)-catalyzed amination of aromatic $\mathrm{C}-\mathrm{H}$ bonds via ring opening of $2 \mathrm{H}$-azirines: Synthesis of 2,3-disubstituted indoles. Org Lett, 2010, 12: 3736-3739

51 Bonamour J, Bolm C. Iron(II) triflate as a catalyst for the synthesis of indoles by intramolecular C-H amination. Org Lett, 2011, 13: 20122014

52 Lucas R L, Powell D R, Borovik A S. Preparation of iron amido 
complexes via putative Fe(IV) imido intermediates. J Am Chem Soc, 2005, 127: 11596-11597

53 Mankad N P, Müller P, Peters J C. Catalytic N-N coupling of aryl azides to yield azoarenes via trigonal bipyramid iron-nitrene intermediates. J Am Chem Soc, 2010, 132: 4083-4085

54 Ni C, Fettinger J C, Long G J, et al. Reaction of a sterically encumbered iron(I) aryl/arene with organoazides: Formation of an iron(V) bis(imide). Chem Commun, 2008, 6045-6047

55 Eckert N A, Vaddadi S, Stoian S, et al. Coordination-number dependence of reactivity in an imidoiron(III) complex. Angew Chem Int Ed, 2006, 45: 6868-6871

56 Cowley R E, Eckert N A, Vaddadi S, et al. Selectivity and mechanism of hydrogen atom transfer by an isolable imidoiron(III) complex. J Am Chem Soc, 2011, 133: 9796-9811

57 Cowley R E, Holland P L. C-H activation by a terminal imidoiron(III) complex to form a cyclopentadienyliron(II) product. Inorg Chim Acta, 2011, 369: 40-44
58 Holland P L. Electronic structure and reactivity of three-coordinate iron complexes. Acc Chem Res, 2008, 41: 905-914

59 King E R, Betley T A. C-H bond amination from a ferrous dipyrromethene complex. Inorg Chem, 2009, 48: 2361-2363

60 King E R, Hennessy E T, Betley T A. Catalytic C-H bond amination from high-spin iron imido complexes. J Am Chem Soc, 2011, 133: 4917-4923

61 Liu P, Wong E L M, Yuen A W H, et al. Highly efficient alkene epoxidation and aziridination catalyzed by iron(II) salt $+4,4^{\prime}, 4^{\prime \prime}$-trichloro-2,2':6',2"-terpyridine/4,4"-dichloro-4'-O-PEG-OCH ${ }_{3}-2,2^{\prime}: 6^{\prime}, 2^{\prime \prime}$ terpyridine. Org Lett, 2008, 10: 3275-3278

62 Ton T M U, Tejo C, Tania S, et al. Iron(II)-catalyzed amidation of aldehydes with iminoiodinanes at room temperature and under microwave-assisted conditions. J Org Chem, 2011, 76: 4894-4904

63 Chen G Q, Xu Z J, Liu Y, et al. Iron-catalyzed nitrene insertion reaction for facile construction of amide compounds. Synlett, 2011, $1174-1178$

Open Access This article is distributed under the terms of the Creative Commons Attribution License which permits any use, distribution, and reproduction in any medium, provided the original author(s) and source are credited. 